\title{
Italy's final position paper on biosimilars and new price and reimbursement pathway
}

\section{Gianluigi Casadei, MD}

\section{The AIFA's position paper recognizes the relevance of biosimilars to ensure the sustainability of drug expenditure but the new price and reimbursement procedure may not favour their prompt market access.}

Keywords: AIFA, biosimilars, market access, position paper, pricing, reimbursement

I $\mathrm{n}$ the final position paper on biosimilars from the Italian Medicines Agency (Agenzia Italiana del Farmaco, AIFA), the relevance of biosimilars is officially acknowledged, representing a significant step forward. But how progressive are AIFA's views?

At the end of May 2013, AIFA released the final version of its position paper on biosimilars [1]. According to AIFA, the availability of biosimilars is key to ensuring sustainability of drug expenditure in decades to come. The European guidelines for pre- and post-marketing development of biosimilars are sufficient to satisfy quality, safety and efficacy comparability with the originator, even in the case of extrapolating safety and efficacy data from the first therapeutic indication to another.

The distinction between interchangeability and substitutability has been comprehensively debated, in practice; AIFA considers that the decision should be left to the prescribing physician. The key role of prescribers seems to prevail also for treatment-naïve patients, although the agency considers that biosimilars should be preferentially prescribed if there is a clear economic benefit for the Italian National Health Service (Servizio Sanitario Nazionale, SSN).

The position paper by AIFA is positive, as it officially recognizes the relevance of biosimilars [2], and this marks a significant step forward. Its approach, however, is still fairly conservative and does not seem to encourage rapid development of the biosimilar market in Italy. This is reflected in the new procedure for granting market access and reimbursement for new drugs [3].

In 2013, law 189/2012, also named Balduzzi's reform after a former Minister of Health, made Italian marketing authorization independent from the pricing and reimbursement process. In fact, AIFA is required by law to grant marketing authorization promptly (within 60 calendar days after the European Medicines Agency's approval) even before negotiation begins. Medicines are not reimbursed and are listed in a newly defined class: C-nn, where ' $\mathrm{C}$ ' stands for 'not reimbursed' and 'nn' stands for 'not negotiated'.

In general, the manufacturer has the option of marketing the drug at its own price and has some flexibility in deciding whether and when, to apply for reimbursement. The degree of flexibility is markedly reduced for generics and biosimilars, for which reimbursement as soon as the originator goes out-of-patent is always key for market uptake, see Figure 1. The law states that biosimilars could be automatically placed in the same reimbursement class of the originator 'without any price negotiation' only if the proposed price is 'obvious convenience'. A proposal that is 'not convenient' can lead to a standby situation of uncertain duration. How is convenience defined? In practice, AIFA has established eight cost categories and set for each of them a minimum percentage discount over the unit price of the originator [4]. It is not clear what cost criteria have been used, but reference to existing discounts for marketed generics

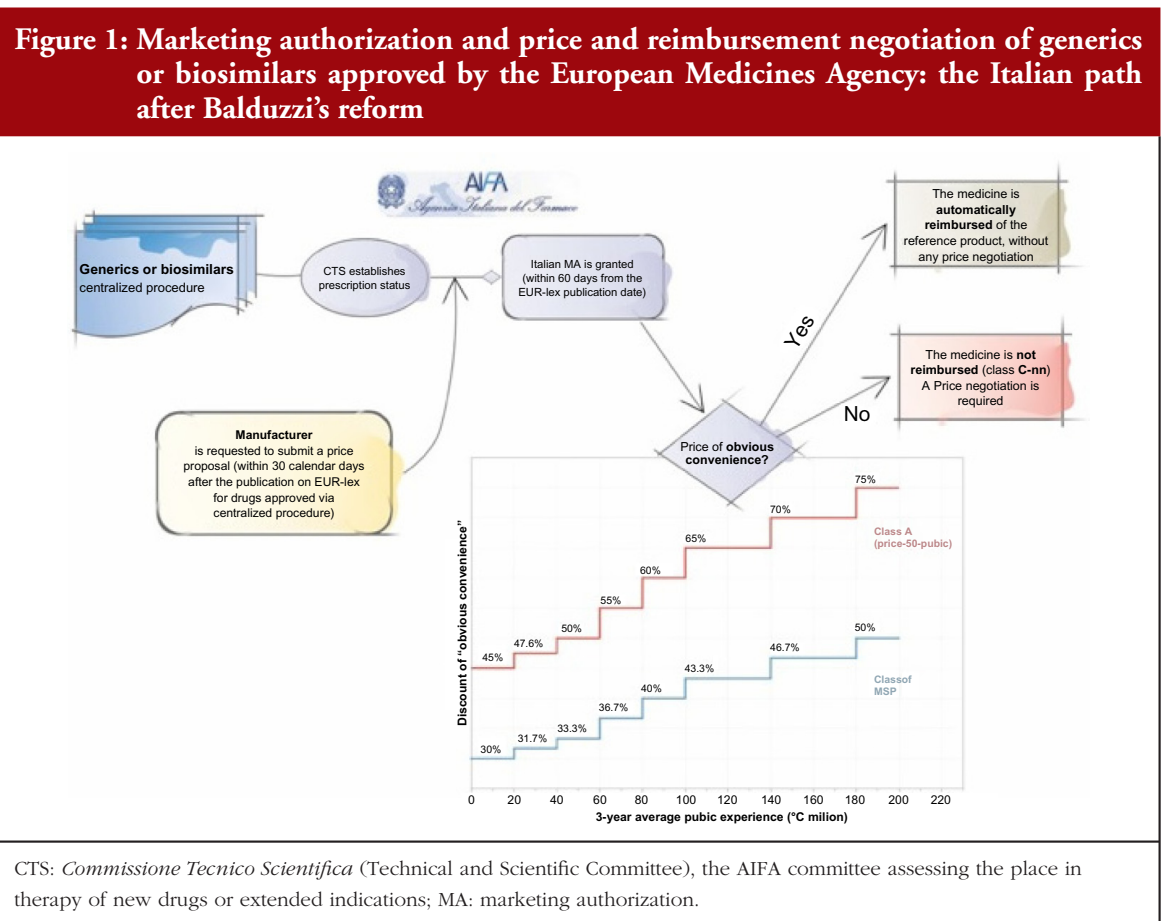

Author: Gianluigi Casadei, MD, Centre for Health Economics (CESAV), Istituto di Ricerche Farmacologiche Mario Negri (IRCCS), Villa Camozzi, IT-20040 Ranica (BG), Italy

Submitted: 26 June 2013; Revised: 10 July 2013; Accepted: 11 July 2013; Published online first: 24 July 2013 


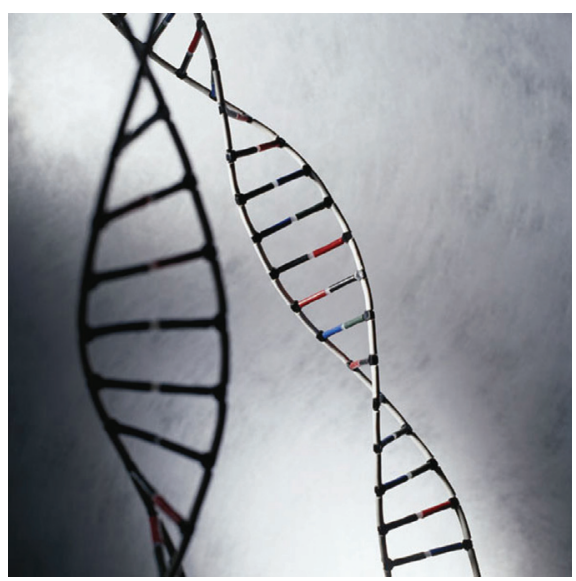

will most certainly have been made. It is also not clear why the same discounts have been applied to generics and biosimilars, perhaps it has been assumed that forcing biosimilars to offer generics-like cheap prices might lead to their faster acceptance and prompt savings for the SSN. Unfortunately, this 'equivalence' seems unsupported. In fact, the American Federal Trade Commission (FTC) has argued that the biosimilar market is different from generics because it has less competition and huge investments are required for developing and producing biologicals. Therefore, it would be reasonable to expect, at most, two or three biosimilar products for each originator. According to FTC, the discount should not be greater than 30\% [5].

Three biologicals, for example, are expected to lose their patents in the next few years: cetuximab (mean annual Italian sales of about Euros 60 million), bevacizumab (Euros 125 million), and trastuzumab (Euros 230 million). The manufacturers of the biosimilars should therefore offer discounts of $36.7 \%$, 43.3\% and $50 \%$, respectively, to avoid potentially time-consuming negotiation. It seems unlikely that there are pharmaceutical companies that accept similar conditions, given the risk that such discounts can become a reference in other European countries. Hence, the 'comparability' of discounts with generics is likely to represent a barrier to entry for biosimilars, and therefore may not be so convenient for the SSN.

\section{Competing interests: None.}

Provenance and peer review: Not commissioned; externally peer reviewed.

\section{References}

1. AIFA. Position paper. I farmaci biosimilari. Rome, 13 May 2013 [homepage on the Internet]. [cited 2013 July 10]. Available from: http://www. agenziafarmaco.gov.it/sites/default/files/AIFA_ POSITION_PAPER_FARMACI_BIOSIMILARI.pdf

2. Haustein R, de Millas C, Höer A, Häussler B. Saving money in the European healthcare systems with biosimilars. Generics and Biosimilars Initiative Journal (GaBI Journal). 2012;1(3-4):120-6. doi:10. 5639/gabij.2012.0103-4.036

3. AIFA. Comunicazione AIFA relativa agli adempimenti successivi all'entrata in vigore della Legge 8 Novembre 2012 N. 189. 7 May 2013 [homepage on the Internet]. [cited 2013 July 10]. Available from: http://www.agenziafarmaco.gov.it/it/content/ comunicazione-aifa-relativa-agli-adempimentisuccessivi-allentrata-vigore-della-legge-8-nove

4. AIFA. Ministero della Salute. Criteri di individuazione degli scaglioni per la negoziazione automatica dei generici e dei biosimilari (Aggiornamento del 08/07/2013) [homepage on the Internet]. [cited 2013 July 10]. Available from: http://www.agenziafarmaco.gov.it/it/content/ criteri-di-individuazione-degli-scaglioni-lanegoziazione-automatica-dei-generici-e-dei-bios

5. Federal Trade Commission. Emerging health care issues: follow-on biologic drug competition. Federal Trade Commission report. June 2009 [homepage on the Internet]. [cited 2013 July 10]. Available from: http://ftc.gov/os/2009/06/ P083901biologicsreport.pdf

DOI: 10.5639/gabij.2013.0203.033

Copyright (c) 2013 Pro Pharma Communications International 